\section{International Scientific Journal Theoretical \& Applied Science}

Department of Mathematics, Gian Jyoti Institute of Management \& Technology, Mohali, Punjab, India

p-ISSN: 2308-4944 (print)

e-ISSN: 2409-0085 (online)

Year: 2015

Issue: 04

Volume: 24

Published: 30.04 .2015

http://T-Science.org
Gaurav Verma

Department of Mathematics, Gobindgarh Public College, Alour, khanna, Punjab, India gkdon85@gmail.com

SECTION 1. Theoretical research in mathematics.

\title{
CREEP TRANSITION OF SPHERICAL SHELL UNDER INTERNAL PRESSURE
}

Abstract: The concept of the generalized strain measures has been useful to solve various elastic, plastic and creep problems. The objective of this paper to solve the creep transition problem in spherical shell under internal pressure using the concept of generalized strain measures and Seth's transition theory of elastic, plastic and creep deformation. The expressions for the creep stresses and yielding are derived by taking the asymptotic behavior of creep transition. The results obtained have been discussed numerically and depicted graphically. The solution obtained does not use the adhoc assumptions given by Tresca or Von Mises.

Key words: Spherical Shell, Creep, Pressure, Stress, Strain.

Language: English

Citation: Gupta S, Verma G (2015) CREEP TRANSITION OF SPHERICAL SHELL UNDER INTERNAL PRESSURE. ISJ Theoretical \& Applied Science 04 (24): 201-207.

Soi: http://s-o-i.org/1.1/TAS*04(24)35 Doi: crossef http://dx.doi.org/10.15863/TAS.2015.04.24.35

\section{INTRODUCTION}

The study of spherical shells is very important for various engineering applications. The elastic, plastic and creep transition problems have paramount importance in the analysis and design of spherical shells. Creep behaviour of spherical shells has been closely investigated by various authors by using Seth's transition theory. Many authors like Rimrott, Wahl, Bailey [1-3] has obtained the creep stresses in the solids by considering the assumptions, like Tresca's yield condition, small deformation, creep strain laws and incompressibility condition. But Seth's transition theory does not use these adhoc assumptions. This theory of transition use the concept of generalized strain measures and by solving the equations of equilibrium, get non linear differential equations from which turning points can be obtained. Turning points are $\pm \infty$ and -1 where \pm cocorrespondents to elastic- plastic transitions and -1 correspond to creep. The transition obtained is treated as asymptotic phenomenon at the turning points. The asymptotic solution through the principal stress difference gives the creep stresses and no semi empirical yield condition is necessary.

Seth [4] has defined the concept of the generalized strain measures as

$$
e_{i j}=\int_{0}^{e_{i j}^{A}}\left[1-2 e_{i j}^{A}\right]^{\frac{n-2}{2}} d e_{i j}^{A}=
$$

$$
=\frac{1}{n}\left[1-\left(1-2 e_{i j}^{A}\right)\right]^{\frac{n}{2}},(i, j=1,2,3)
$$

Where $\mathrm{n}$ is the measure and $e_{i j}^{A}$ are the almansi finite strain components. In the terms of the almansi strain components $e_{i j}^{A}$, [5] the principal components of the generalized strain measures are given as

$$
e_{i j}^{M}=\left[\frac{1}{n}\left\{1-\left(1-2 e_{i j}^{A}\right)^{\frac{n}{2}}\right\}\right]^{m}
$$

Where $\mathrm{m}, \mathrm{n}$ are measure exponents and $e_{i j}^{A}$ are principal components of $e_{i j}^{M}$. These generalized strain measures can be reduced to the other strain measures for different set of $m$ and $n$ values.

\section{GOVERNING DIFFERENTIAL EQUATIONS}

We consider a spherical shell of constant thickness under internal pressure having internal and external radii $a$ and $b$ respectively. Due to the symmetry of spherical shell, the displacement is purely radial. Therefore, the components of displacement in spherical coordinates $(r, \theta, \phi)$ are given as:

$$
\mathrm{u}=\mathrm{r}(1-\beta), \mathrm{v}=0, \mathrm{w}=0
$$

where $\beta$ is function of $r$ only.

The generalized components of strain are given by equation (2) as:

$$
e_{r r}=\frac{1}{n^{m}}\left[1-\left(r \beta^{\prime}+\beta\right)^{n}\right]^{m}
$$




$$
\begin{gathered}
e_{\theta \theta}=\frac{1}{n^{m}}\left[1-\beta^{n}\right]^{m}=e_{\phi \phi} \\
e_{r \theta}=e_{r \phi}=e_{\theta \phi}=0
\end{gathered}
$$

where $\beta^{\prime}=\frac{d \beta}{d r}$

The stress - strain relations for isotropic material are given by [6].

$$
T_{i j}=\lambda \delta_{i j} I_{1}+2 \mu e_{i j}, \quad(i, j=1,2,3)
$$

Using the equation (4) in the equation (5) having stress strain relations.

$$
\begin{gathered}
T_{r r}=\frac{\lambda+2 \mu}{n^{m}}\left[1-\left(r \beta^{\prime}+\beta\right)^{n}\right]^{m}+\frac{2 \lambda}{n^{m}}\left[1-\beta^{n}\right]^{m} \\
T_{\theta \theta}=T_{\phi \phi}=\frac{\lambda}{n^{m}}\left[1-\left(r \beta^{\prime}+\beta\right)^{n}\right]^{m}+\frac{2 \lambda+2 \mu}{n^{m}}\left[1-\beta^{n}\right]^{m} \\
T_{r \theta}=T_{r \phi}=T_{\theta \phi}=0
\end{gathered}
$$
except

The equations of equilibrium are all satisfied

$$
\frac{d T_{r r}}{d r}+\frac{2\left(T_{r r}-T_{\theta \theta}\right)}{r}=0
$$

Using equation (6) in (7), we get the non - linear differential equation in $\beta$ as

$$
\begin{aligned}
& P \beta(1+P)^{n-1}\left[1-\beta^{n}(1+P)^{n}\right]^{m-1} \frac{d P}{d \beta} \\
& +\left[1-\beta^{n}(1+P)^{n}\right]^{m-1} P(1+P)^{n}-2(1- \\
& \text { c) }\left[1-\beta^{n}\right]^{m-1} P+\frac{2 c}{m n \beta^{n}}\left[\left\{1-\beta^{n}(1+\right.\right.
\end{aligned}
$$

Impact Factor ESJI $(\mathrm{KZ}) \quad=\mathbf{1 . 0 4 2}$

$$
\left.\left.P)^{n}\right\}^{m-1}-\left\{1-\beta^{n}\right\}^{m}\right]=0
$$

Where $c=2 \mu / \lambda+2 \mu$ is the compressibility factor and $\mathrm{r} \beta^{\prime}=\beta \mathrm{P}$ such that $\mathrm{P}$ is function of $\beta$ and $\beta$ is the function of $\mathrm{r}$. Turning points of $\beta$ from equation (8) are $P \rightarrow-1$ and $P \rightarrow \pm \infty$ where the transition points $P \rightarrow \pm \infty$ corresponds to elasticplastic transition and $P \rightarrow-1$ is related to creep transition. Therefore, we take into the consideration the case only $P \rightarrow-1$.

\section{III .SOlution Through Principal STRESS DIFFERENCE}

In order to calculate the creep stresses, we define the transition function $\mathrm{R}=\left(T_{r r}-T_{\theta \theta}\right)$ through the principal stress difference as taken by Seth, Hulsarkar, Gupta [4, 5, 7].

$$
\begin{aligned}
\left(T_{r r}-T_{\theta \theta}\right)= & \frac{2 \mu}{m n}\left[\left[\left\{1-\beta^{n}(1+P)^{n}\right\}^{m}-\right.\right. \\
& \left.\left.\left\{1-\beta^{n}\right\}^{m}\right]\right]
\end{aligned}
$$

On taking the logarithmic differentiation with respect to $\beta$, we get,

$$
\frac{d(\log R)}{d \beta}=m n \times \frac{\left\{1-\beta^{n}(1+P)^{n}\right\}^{m-1}\left[-\beta^{n-1}(1+P)^{n}-\beta^{n}(1+P)^{n-1} \frac{d P}{d \beta}\right]+\left\{1-\beta^{n}\right\}^{m-1} \beta^{n-1}}{\left[\left\{1-\beta^{n}(1+P)^{n}\right\}^{m}-\left\{1-\beta^{n}\right\}^{m}\right]}
$$

Using the value of $\frac{d P}{d \beta}$ from equation (8) in (10), we get as

$$
\frac{d(\log R)}{d \beta}=m n \beta^{n-1} \frac{2(1-c)\left\{1-\beta^{n}\right\}^{m-1}+\left\{1-\beta^{n}\right\}^{m-1}-\frac{2 c}{m n \beta^{n}}\left[\left\{1-\beta^{n}(1+P)^{n}\right\}^{m}-\left\{1-\beta^{n}\right\}^{m}\right]}{\left[\left\{1-\beta^{n}(1+P)^{n}\right\}^{m}-\left\{1-\beta^{n}\right\}^{m}\right]}
$$

By taking the asymptotic value at $P \rightarrow-1$, the equation (11) becomes

$$
\frac{d(\log R)}{d \beta}=\frac{m n\left\{1-\beta^{n}\right\}^{m-1} \beta^{n-1}(3-2 c)}{\left[1-\left(1-\beta^{n}\right)^{m}\right]}+\frac{2 c}{\beta}
$$

Integrate eq. (12) with respect to $\beta$, we have

$$
R=A_{0} r^{-2 c}\left[1-\left(1-\beta^{n}\right)^{m}\right]^{3-2 c}
$$

where $A_{0}$ is the constant of integration.

The asymptotic value of $\beta$ when $P \rightarrow-1$ is given by $\mathrm{D} / \mathrm{r}$ where $\mathrm{D}$ is constant. Using the value of $\beta$ in eq. (13), we have

$$
\begin{array}{r}
R=\left(T_{r r}-T_{\theta \theta}\right)=A_{0} r^{-2 c}[1 \\
\left.-\left(1-D^{n} r^{-n}\right)^{m}\right]^{3-2 c}
\end{array}
$$

We can find the value of $T_{r r}$ using the eq. (14) in the eq. (7).

$$
\begin{gathered}
T_{r r}=-2 A_{0} \int r^{-2 c-1}[1-(1- \\
\left.\left.D^{n} r^{-n}\right)^{m}\right]^{3-2 c} d r+A_{1}
\end{gathered}
$$


where $A_{1}$ is the constant of the integration and can be find using the following boundary conditions. The boundary condition for the spherical shell under internal pressure is given by [5].

$$
T_{r r}=-p \quad \text { at } \mathrm{r}=\mathrm{a} \text { and } \quad T_{r r}=0 \quad \text { at } \mathrm{r}=\mathrm{b} .
$$

Therefore, the values of constants are

$A_{1}=\left[2 A_{0} \int r^{-2 c-1}\left[1-\left(1-D^{n} r^{-n}\right)^{m}\right]^{3-2 c} d r\right]_{r=b}$

$$
A_{0}=\frac{-p}{2 \int_{a}^{b} r^{-2 c-1}\left[1-\left(1-D^{n} r^{-n}\right)^{m}\right]^{3-2 c} d r}
$$

Put the values of these constants $A_{0}$ and $A_{1}$ in the eq. (14) and (15), we get as

$$
\begin{aligned}
& T_{r r}=-p \frac{\int_{r}^{b} r^{-2 c-1}\left[1-\left(1-D^{n} r^{-n}\right)^{m}\right]^{3-2 c} d r}{2 \int_{a}^{b} r^{-2 c-1}\left[1-\left(1-D^{n} r^{-n}\right)^{m}\right]^{3-2 c} d r} \\
& T_{\theta \theta}=T_{\phi \phi}=T_{r r} \\
& +\frac{p r^{-2 c}\left[1-\left(1-D^{n} r^{-n}\right)^{m}\right]^{3-2 c}}{2 \int_{a}^{b} r^{-2 c-1}\left[1-\left(1-D^{n} r^{-n}\right)^{m}\right]^{3-2 c} d r}
\end{aligned}
$$

Eq. (14) represents single stage of the creep. If we have to show all three stages of the creep, we shall add the increment value of $\left(T_{r r}-T_{\theta \theta}\right)$ as $[5$, 8]. Therefore, we have

$$
\begin{gathered}
R=\left(T_{r r}-T_{\theta \theta}\right)=A_{0} r^{-6 c-3} \prod_{m, n}[1- \\
\left.\left(1-D^{n} r^{-n}\right)^{m}\right]^{3-2 c}
\end{gathered}
$$

Where $m$ and $n$ have three set values which are corresponding to one stage of the creep and the transitional creep stresses are given as:

$$
\begin{aligned}
& T_{r r}=-p \frac{\int_{r}^{b} r^{-6 c-3} \prod_{m, n}\left[1-\left(1-D^{n} r^{-n}\right)^{m}\right]^{3-2 c} d r}{2 \int_{a}^{b} r^{-6 c-3} \prod_{m, n}\left[1-\left(1-D^{n} r^{-n}\right)^{m}\right]^{3-2 c} d r} \\
& T_{\theta \theta}=T_{\phi \phi}=T_{r r}+ \\
& \frac{p r^{-6 c-3} \prod_{m, n}\left[1-\left(1-D^{n} r^{-n}\right)^{m}\right]^{3-2 c}}{2 \int_{a}^{b} r^{-6 c-3} \prod_{m, n}\left[1-\left(1-D^{n} r^{-n}\right)^{m}\right]^{3-2 c} d r}
\end{aligned}
$$

\section{STEAdy STATE OF CREeP}

The secondary stage of the creep is treated as the steady state and the transitional creep stresses for this stage can be obtained by taking $m=1$ in the equation (19). Therefore, we get as

$$
\begin{gathered}
T_{r r}=-p \frac{\int_{r}^{b} r^{-3 n+2 c(n-1)-1} d r}{2 \int_{a}^{b} r^{-3 n+2 c(n-1)-1} d r} \\
T_{r r}=-p \frac{\left[\left(\frac{b}{r}\right)^{3 n-2 c(n-1)}-1\right]}{\left[\left(\frac{b}{a}\right)^{3 n-2 c(n-1)}-1\right]} \\
T_{\theta \theta}=T_{\phi \phi}=T_{r r}+\frac{p r^{-3 n+2 c(n-1)}}{2 \int_{a}^{b} r^{-3 n+2 c(n-1)-1} d r} \\
T_{\theta \theta}=p \frac{\frac{1}{2}[n(3-2 c)-2(1-c)]\left(\frac{b}{r}\right)^{3 n-2 c(n-1)}+1}{\left(\frac{b}{a}\right)^{3 n-2 c(n-1)}-1}
\end{gathered}
$$

Results obtained are same as given by Hulsarkar[9] for the isotropic materials. It is also noted that the value of $\left|T_{r r}-T_{\theta \theta}\right|$ is maximum at $\mathrm{r}$ $=$ a. Therefore, the initial yielding starts at the internal surface of the spherical shell given as

$$
\begin{aligned}
& \mathrm{Y}(\text { yield stress })=\left|T_{r r}-T_{\theta \theta}\right|= \\
& \frac{p a^{-3 n+2 c(n-1)}}{2 \int_{a}^{b} r^{-3 n+2 c(n-1)-1} d r}
\end{aligned}
$$

From eq. (23), we can define the yielding ratio as

$$
\frac{\mathrm{Y}}{\mathrm{p}}=\frac{-3 n+2 c(n-1)}{2\left(\frac{b}{a}\right)^{3 n-2 c(n-1)}-1}
$$

\section{YIELDING RATIO FOR DIFFERENT THICKNESS RATIO For n=2}

\begin{tabular}{|l|l|l|l|l|}
\hline \multirow{2}{*}{ Thickness ratio $\left(\frac{b}{a}\right)$} & \multicolumn{4}{|c|}{ Yielding ratio } \\
\cline { 2 - 5 } & $\mathrm{C}=0$ & $\mathrm{C}=0.25$ & $\mathrm{C}=0.50$ & $\mathrm{C}=0.75$ \\
\hline 2 & 3.0470 & 2.8121 & 2.5806 & 2.3500 \\
\hline 3 & 3.0042 & 2.7565 & 2.5103 & 2.2663 \\
\hline 4 & 3.0009 & 2.7513 & 2.5024 & 2.2500 \\
\hline
\end{tabular}




\section{YIELDING RATIO FOR DIFFERENT THICKNESS RATIO For $\mathbf{n = 3}$}

TABLE 2

\begin{tabular}{|l|l|l|l|l|}
\hline \multirow{2}{*}{ Thickness ratio $\left(\frac{b}{a}\right)$} & \multicolumn{4}{|c|}{ Yielding ratio } \\
\cline { 2 - 5 } & $\mathrm{C}=0$ & $\mathrm{C}=0.25$ & $\mathrm{C}=0.50$ & $\mathrm{C}=0.75$ \\
\hline 2 & 4.5090 & 4.0157 & 3.5275 & 3.0476 \\
\hline 3 & 4.5004 & 4.0006 & 3.5016 & 3.0041 \\
\hline 4 & 4.5000 & 4.0000 & 3.5002 & 3.0007 \\
\hline
\end{tabular}

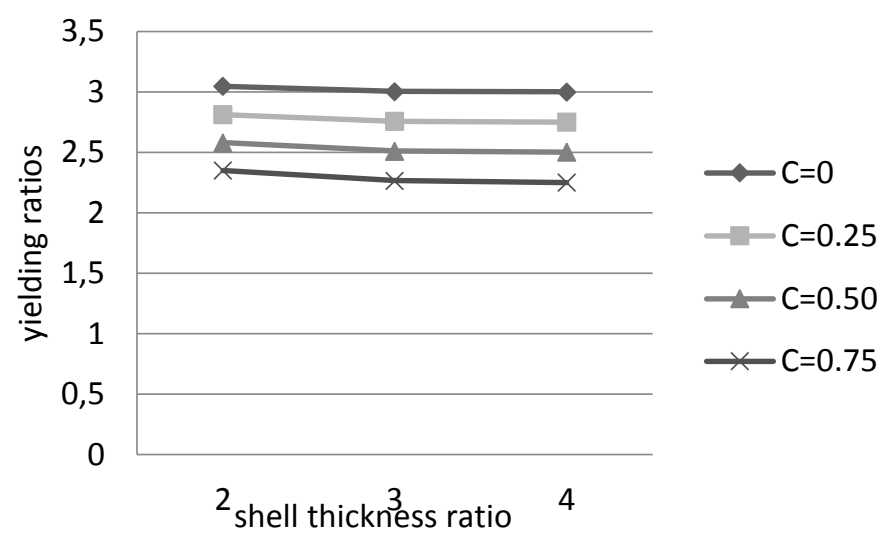

Figure 1 - Yielding ratio for different thickness ratio for $n=2$.

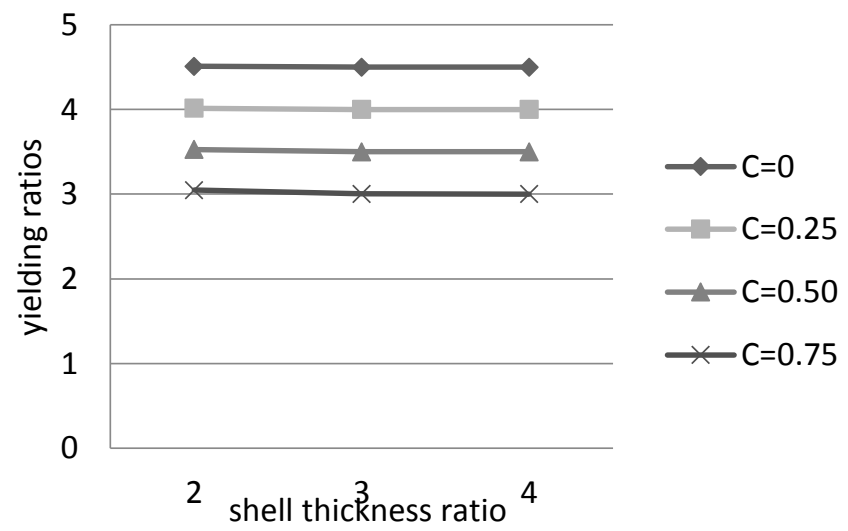

Figure 2 - Yielding ratio for different thickness ratio for $n=3$.

In the fig. 1 and fig.2, the graph have been plotted between the shell thickness ratio and yielding ratios for $n=2$ and $n=3$ respectively. It is seen that yielding is higher in the spherical shells having lesser thickness ratio. Therefore, the pressure required to yield in thinner shells as compared to thicker shell is more.

Incompressible material:
As a particular case, we obtain the transitional creep stresses for compressible material by approaching c to zero. Therefore eq. (21) and (22) become as

$$
T_{r r}=-p \frac{\left[\left(\frac{b}{r}\right)^{3 n}-1\right]}{\left[\left(\frac{b}{a}\right)^{3 n}-1\right]},
$$

$$
T_{\theta \theta}=p \frac{\frac{1}{2}[3 n-2]\left(\frac{b}{r}\right)^{3 n}+1}{\left(\frac{b}{a}\right)^{3 n}-1}
$$


In order to find the Creep stresses, we introduce the non-dimensional components as following:

$$
\mathrm{R}=\mathrm{r} / \mathrm{b}, R_{o}=\mathrm{a} / \mathrm{b}, \sigma_{r}=T_{r r} / p, \sigma_{\theta}=T_{\theta \theta} / p .
$$

Therefore, the equations (21), (22) in magnitude are given as

$$
\begin{aligned}
\sigma_{r} & =\frac{\left[(\mathrm{R})^{-3 n+2 c(n-1)}-1\right]}{\left[\left(R_{O}\right)^{-3 n+2 c(n-1)}-1\right]} \\
\sigma_{\theta} & =\frac{\frac{1}{2}[n(3-2 c)-2(1-c)](\mathrm{R})^{-3 n+2 c(n-1)}+1}{\left(R_{O}\right)^{-3 n+2 c(n-1)}-1}
\end{aligned}
$$

For incompressible material,

$$
\sigma_{r}=\frac{\left[(\mathrm{R})^{-3 n}-1\right]}{\left[\left(R_{O}\right)^{-3 n}-1\right]}, \quad \sigma_{\theta}=\frac{\frac{1}{2}[3 n-2](\mathrm{R})^{-3 n}+1}{\left(R_{O}\right)^{-3 n_{-}}+1}
$$

Further the creep strain rates can be calculated for this creep transition problem of spherical shell under internal pressure. For this, Creep sets in the strain should be replaced by creep strain rates and the stress-strain relation is given by [11].

$$
e_{l j}=\frac{1+\mathrm{v}}{E} T_{\theta \theta}-\frac{\sigma}{E} \delta_{i j} \theta
$$

where $\dot{e_{l j}}$ is the strain tensor with respect to parameter $t$ and $v=\frac{1-c}{2-c}$ is the poisson ratio.

On differentiation of equation (1.4) with respect to $t$ at $m=1$

$$
\mathrm{e}_{\theta \theta}=-\beta^{\mathrm{n}-1} \dot{\beta}
$$

If $\varepsilon_{\theta \theta}$ is the Cauchy strain measure, then

$$
\dot{\varepsilon_{\theta \theta}}=-\dot{\beta}
$$

Now when $P \rightarrow-1$ in equation (1.9) for $\mathrm{m}=1$, we get the transition value of $\beta$ as

$$
\beta=\left[\frac{n}{2 \mu}\left(T_{r r}-T_{\theta \theta}\right)\right]^{\frac{1}{n}}
$$

By using equations (29), (30),(31) in equation (28), we get expression for creep strains.

$$
\begin{aligned}
& \dot{\varepsilon_{r r}}=k\left[T_{r r}-\left(\frac{1-\mathrm{c}}{2-\mathrm{c}}\right)\left(T_{\phi \phi}+T_{\theta \theta}\right)\right] \\
& \dot{\varepsilon_{\theta \theta}}=k\left[T_{\theta \theta}-\left(\frac{1-\mathrm{c}}{2-\mathrm{c}}\right)\left(T_{r r}+T_{\theta \theta}\right)\right] \\
& \dot{\varepsilon_{\phi \phi}}=k\left[T_{\phi \phi}-\left(\frac{1-\mathrm{c}}{2-\mathrm{c}}\right)\left(T_{r r}+T_{\theta \theta}\right)\right]
\end{aligned}
$$

where $k=\left[\frac{n}{2 \mu}\left(T_{r r}-T_{\theta \theta}\right)\right]^{\frac{1}{n}} \times \frac{1}{E}$. These equations are similar with the results given by Bailey[12] for creep strains. These are known as constitutive equations useful for finding creep stresses.

\section{NUMERICAL DISCUSSION}

The figures 1, 2 are drawn to calculate the yielding and pressure for different shell thickness ratio. It is observed that yielding is higher in shells having lesser thickness ratio and the pressure required to yield in thinner shells as compared to thicker shell is more. In the figure $(3,4,5,6)$, curves have been drawn between stresses and the radii ratios $\mathrm{R}=\mathrm{r} / \mathrm{b}$ with different compressibility factors. It is noted that stresses are maximum at the internal surface of shells and stresses obtained for the incompressible materials are more than the stresses in the compressible materials. Therefore, we can say that the spherical shells made of the incompressible material need high pressure to yield as compared to spherical shell made of the compressible material. It is also concluded that secondary creep or steady state are applicable for $\mathrm{m}=1$, where as the primary and tertiary creep stresses can be obtained for any value of $m$. The graphs have drawn similar with Guven[10] in the elastic-plastic problem of rotating disk with rigid inclusion.

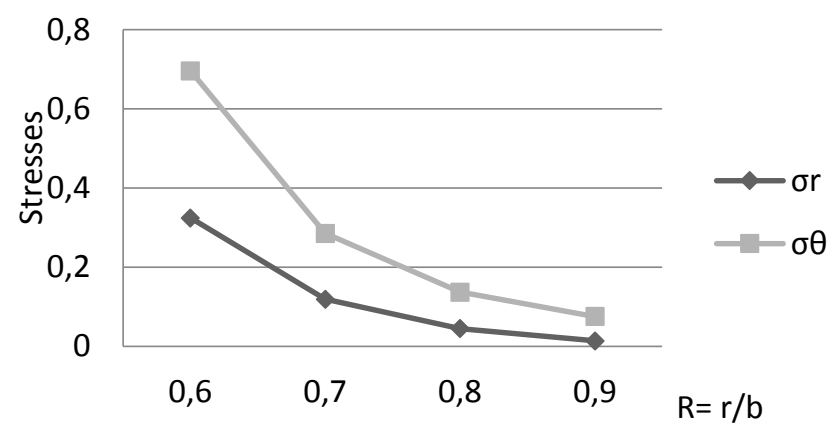

Figure 3 - Stresses drawn for different $\operatorname{radii} \operatorname{ratios}(\mathrm{C}=0)$. 


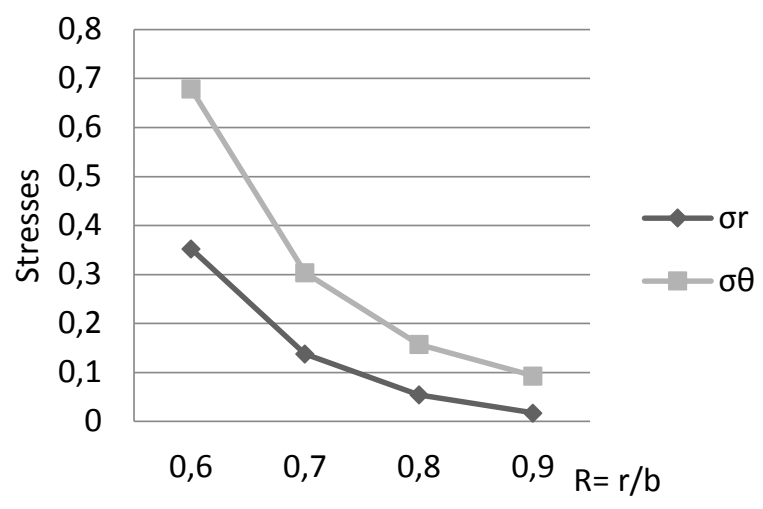

Figure 4 - Stresses drawn for different $\operatorname{radii} \operatorname{ratios}(\mathrm{C}=\mathbf{0 . 2 5})$.

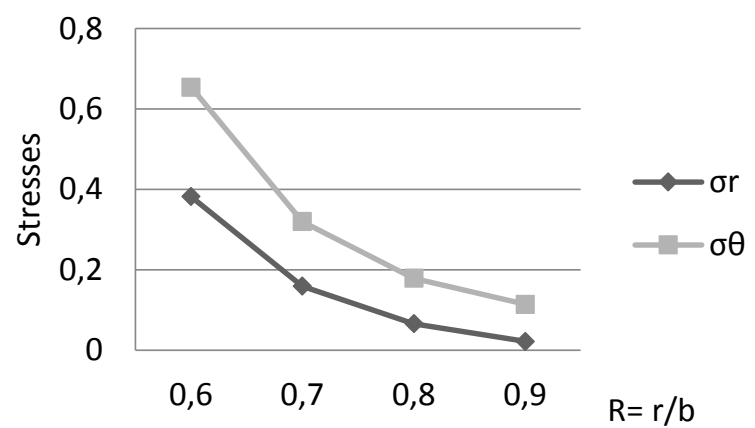

Figure 5 - Stresses drawn for different $\operatorname{radii} \operatorname{ratios}(\mathrm{C}=0.50)$.

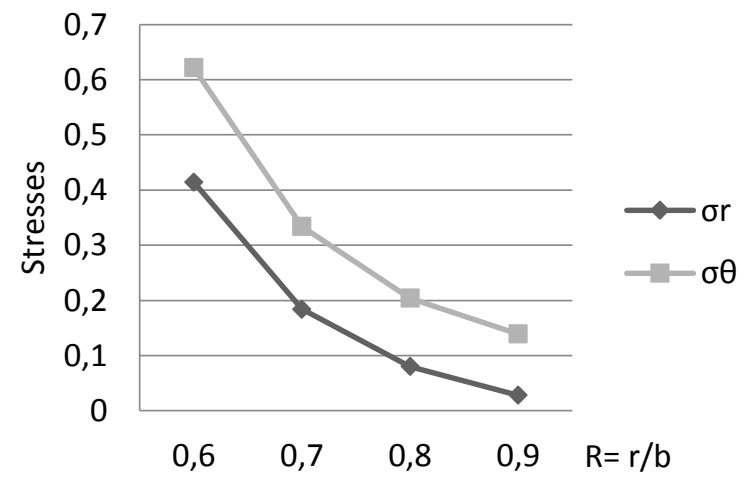

Figure 6 - Stresses drawn for different $\operatorname{radii} \operatorname{ratios}(C=0.75)$. 


\section{Nomenclature:}

$e_{i j}^{A} \quad-$ Principal finite strain component

$\mathrm{u}, \mathrm{v}, \mathrm{w}$ - displacement components, [m]

$r, \theta, \phi$ - Radial, circumferential and axial directions respectively

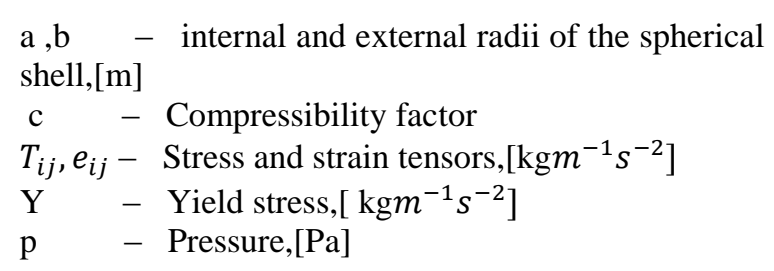

\section{References:}

1. Rimrott FPJ (1959) Creep of thick walled tubes under internal pressure considering large strains. J. applied Mech; 1959, 29, 271.

2. Wahl AM (1957) Stress distributions in rotating discs subjected to creep at elevated temp. Transactions ASME, 1957, 79, 299-05.

3. Bailey RW (1951) Creep Relationships and their applications to Pipes, Tubes and Cylinder Parts under Internal Pressure, Proc. Inst. Mech. Engnrs.,164(1951), 1, pp.1-131.

4. Seth BR (1966) "Measure Concept in Mechanics", Int. J. Non-linear Mech., Vol.1, pp. $35-40,1966$.

5. Hulsarkar S (1980) "Creep Transitions in Anisotropic shells under uniform pressure".
Indian J.Pure applied math, 11(6): 693-698, June 1980.

6. Sokolnikoff IS (1946) "THE Mathematical Theory of Elasticity", MCGRAW Hill, 1946.

7. Gupta SK (2001) Sonia. Pathak, Thermo Creep Transition in thick walled circular -cylinder under internal pressure, Indian. J. Pure appl. Math., 32(2): 237-253, Feb. 2001.

8. Seth BR (1972) Creep transition, J. Math. Phys. Sci., 8(1972), pp. 1-2.

9. Hulsarkar S (1966) "Transition theory of Creep of shell under uniform pressure. ZAMM, 46(1966), 7, pp. 431-437.

10. Given U (1999) "Elastic-Plastic Rotating disk with rigid Inclusion", Mech.Structure and Mechanics., vol.27,pp.117-128, 1999. 